\title{
Chapter 5 \\ Realities and Challenges of Land Issues in the Era of Depopulation
}

\author{
Shoko Yoshihara
}

\begin{abstract}
Abandoned and unclaimed land has emerged as a major policy issue in Japan, where the population is dwindling and property values are falling in many areas, including big cities. This article analyzes this alarming issue using the results of a nationwide survey conducted by the author targeting 1719 local authorities, which revealed a disconnection between the existing landownership system and rapid demographic change. Policy initiatives are needed to address three basic challenges, namely, how to get people to register title transfers when they inherit real estate; how to protect and manage land that has no immediate prospect for use; and how to improve the data collection and management infrastructure.
\end{abstract}

Keywords Unknown owners · Depopulation · Landownership · Inheritance · Registration

\subsection{Emergence of Land of Unknown Ownership}

While rural areas are depopulated and land prices continue to decrease, there have been reports from across Japan regarding cases of what is referred to as "lands of unknown ownership" for which the location or existence of the owner cannot immediately be determined. This is an obstacle to local public interest in terms of issues such as post-disaster recovery, elimination of abandoned farmlands, and countermeasures against vacant properties.

On October 26, 2017, an announcement was made by the Abandoned and Unclaimed Land Issues Research Group, founded by former Minister of Internal Affairs and Communications Hiroya Masuda and others, stating that, if things remain as they are, abandoned and unclaimed land will increase to approximately 7.2 million hectares by 2040 , causing a total economic loss of approximately

\footnotetext{
S. Yoshihara $(\bowtie)$

Tokyo Foundation for Policy Research, Tokyo, Japan

e-mail: yoshihara@tkfd.or.jp 
6 trillion yen, thus making the issue a topic of public interest (Preliminary Data 2017).

\subsection{Issue of Unregistered Inheritances}

A major factor in being unable to determine the whereabouts or existence of the landowner is the issue of unregistered inheritances. Generally, when the owner of land or property dies, the inheritor who is the new owner carries out the procedures to register the inheritance and to transfer the title on the real estate register to his or her own name. However, inheritance registration is not an obligation, and making the decision as to whether and when the title transfer procedure should be made is left to the judgment of the inheritor.

For that reason, if inheritance registration is not performed, the title on the real estate register is left in the name of the deceased, and the land is in actuality used by one of their heirs. Later, as time passes and generations come and go, the legal inheritors grow exponentially, and the information on the registry becomes detached from the actual situation.

This situation is not illegal per se because inheritance registration is voluntary rather than obligatory. However, it is an obstacle in cases where a third party wishes to contact the owner and there are talks about newly using such land. In order to make use of such land, first, the legal inheritor must be specified by researching the kinship of all inheritors and making an inheritance succession chart based on official copies of the family registry with all inheritors and on the copies of their certificates of residence. Subsequently, consent must be obtained from all inheritors for the register title transfer.

This process requires even more time and expense if, for example, there is even one person among the inheritors who cannot be contacted due to their whereabouts being unknown or because they are living overseas.

In recent years, unregistered inheritance has become a nationwide issue due to land becoming unusable because the whereabouts of the owner are unknown.

\subsection{Local Authorities "Have Had Problems"}

What, then, is the actual situation across Japan? Tokyo Foundation for Policy Research, a private think tank, conducted a survey among tax offices in 1718 municipalities and in metropolitan Tokyo (23 wards) in the autumn of 2014 in order to quantitatively understand the realities of this issue (Tokyo Foundation for Policy Research 2016). The aim was to understand the reality of "unknown ownership," albeit indirectly, by investigating the occurrence of issues such as specifying fixed property taxpayers (landowners) for unregistered inheritances. Responses were obtained from 888 local authorities nationwide (response ratio: 52\%). 


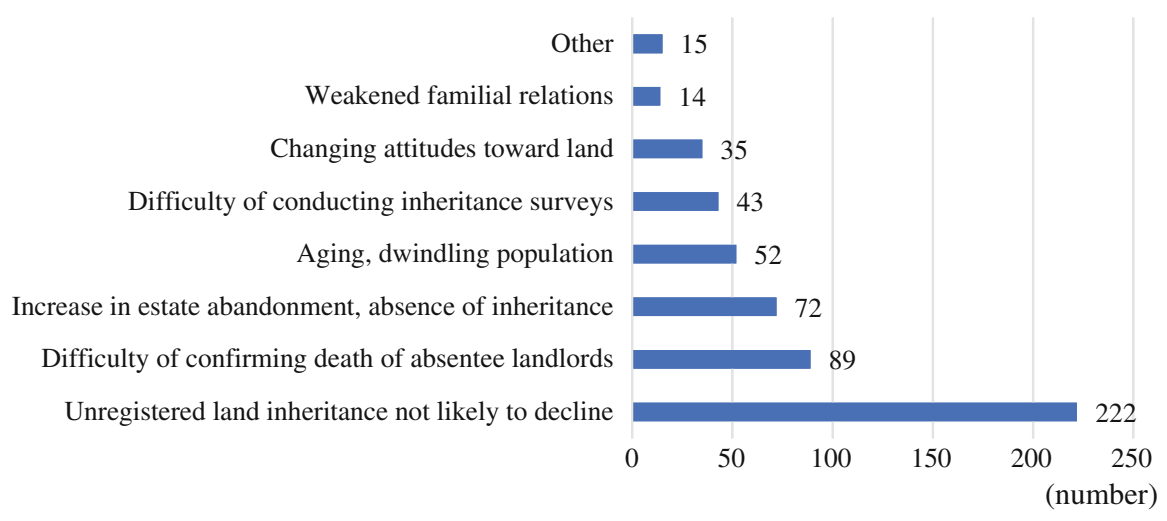

Fig. 5.1 Reasons for increase in decedent tax. Source: Tokyo Foundation for Policy Research "Unknown ownership of land-the reality of issues demonstrated by a survey of local authorities" 2016

Five hundred fifty-seven (63\%) of the local authorities responded "Yes" to the question, "Have you ever experienced problems due to being unable to specify a landowner?"

With regard to the multiple choice question about the specific type of issue, the highest response rate was for "Difficulty in collecting fixed property tax" (486 local authorities), followed, in almost equal numbers, by "Registration of deteriorated vacant properties as dangerous properties" (253 local authorities) and "Decay of land due to neglect" (238 local authorities).

Next, "decedent tax" was investigated. One hundred forty-six local authorities (16\%) responded affirmatively regarding cases of unregistered inheritances in which the tax office had not followed up on investigating the inheritor, and tax had inevitably remained in the name of the deceased person. The ratio of taxpayers (who were not subject to land tax exemptions) was $6.5 \%$. Seven local authorities (1\%) responded negatively. Seven hundred thirty-five local authorities (83\%) responded "Unknown," which shows the difficulty of accurately understanding whether owners are still living.

They were subsequently asked whether they believed that decedent tax would increase in the future.

As a result, 770 local authorities (87\%) said "Yes" or "Probably."

When asking about the reasons for this in a descriptive format, the responses were largely split between institutional factors and social factors. First, with regard to institutional factors, 222 local authorities said that the increase in unregistered inheritances was due to the complexity of procedures and the major expense among other factors. Furthermore, some of the responses also pointed out that it is difficult to find out about the death of a person living outside the municipality, and that inheritance surveys are difficult to conduct due to the increase in absentee landlords (Fig. 5.1: Shaded bars). 


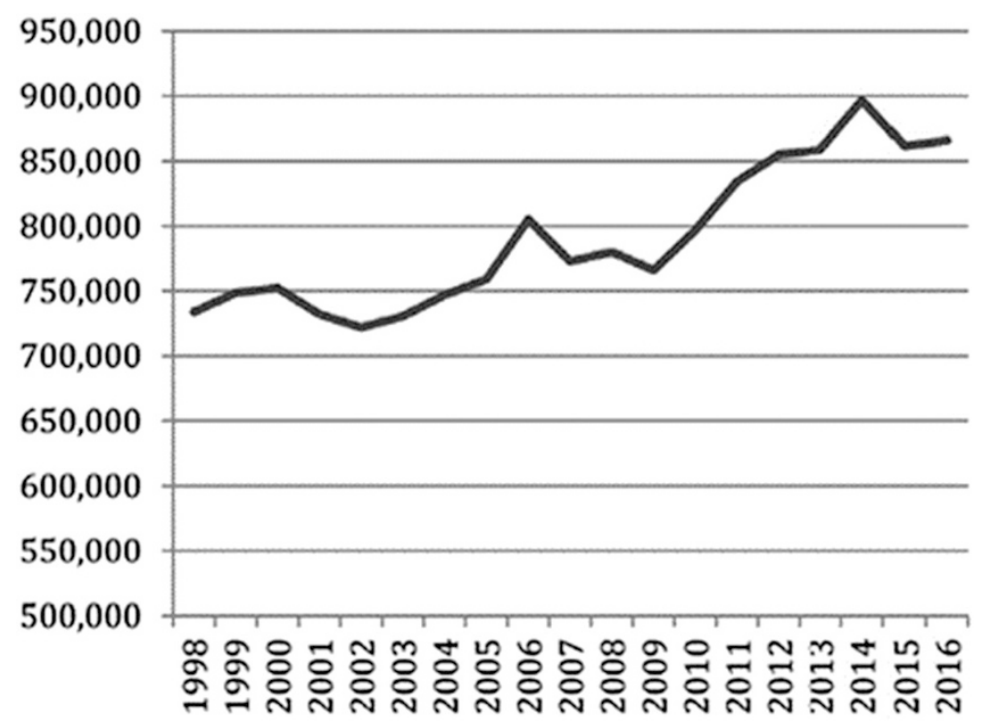

Fig. 5.2 Transition in title transfer registration due to inheritance, etc. (1998-2016). Source: Produced by the author based on registration statistics from the Ministry of Justice (n.d.)

In the case of the death of a taxpayer who is not registered as a resident by the local authorities (absentee landlord), there are no structures in the current system for notifying the local authority concerned of the death. For that reason, as long as there is no tax payment notification submission or arrears and no report from the inheritor, it is difficult to find out about the death of the taxpayer if inheritance registration is not performed. In addition, the inheritance survey may be further complicated when the owner's certificate of residence has been disposed of after the retention period (usually five years) following the death of the owner or transfer of residence.

Next, the social factors that were cited include increased estate abandonment due to low land asset values and the burden of managing the property, and the difficulty of cooperating on the partition of the estate due to weakened familial relations.

Specifically, the answers included statements such as the following: "land trading has stagnated, and, increasingly, substantial problems do not initially arise even if inheritance registration has not been correctly carried out"; "the inheritor no long lives in the area, and many people do not know the location of the land that they own, such as mountain forests and fields"; "there are many cases in which the land is a burden (in terms of annual tax) rather than being profitable, so the inheritors do not want to take it on"; and "there is a low value to fixed properties in depopulated areas, so, increasingly, the children of the owners do not return to the local area and have less of an attachment to the property."

Furthermore, among the responses, regarding the handling of land with absentee owners due to inheritance abandonment, some commented that, although there are systems for inheritance asset management, for example, there are many examples in 
which land is inevitably neglected as it is not thought to be cost effective, which, in reality, leads to institutional or legal challenges because of the uncertainty relating to the responsibilities for managing the land and determining the identity of the rights holder.

These results bring the overall structure of this gradually emerging issue to the surface, which shows that the difficulty of finding landowners (taxpayers) is due to societal changes such as depopulation and an aging society as well as the inflexibility of the current system.

\subsection{This Issue Will Inevitably Worsen If Nothing Is Done}

Two observations can be made based on the results of these surveys. First, the issue of land of "unknown ownership" is not a temporary or local issue; rather, it is affecting local authorities across Japan on a regular basis. Second, flaws in the system are fostering this issue.

The foundations for understanding information regarding the actual ownership and use of land in Japan are lacking. Various registers have been produced with different objectives, such as the real estate register, fixed property tax ledger, and the agricultural land register. However, the content and accuracy of these registers are not consistent, and there are no structures that enable a centralized understanding of this information. The national land survey (definition of areas, boundaries, owners, etc., for sections of land), which is the foundation for national land management, is only 50\% complete, despite having started in 1951. Meanwhile, in comparison to other countries, individual ownership rights are extremely strong.

Of the various registers, although the real estate register is a source of important owner information, the registration of the individual ownership right is voluntary, as stated above. The real estate registration system is a structure that was originally intended to protect rights and ensure the safety of transactions, and it is not a system that enables the government to understand landowner information. Even if registration is made, the owner on the registry is not obligated to provide a notification of the change of address after moving house.

The foundation of land information in Japan is formed of structures in which accuracy is affected by market trends and personal actions. When viewing a given piece of land as a constituent of national land, a major challenge is that the establishment of information, which is the basis for the land policy, is dependent on individual discretion. This issue has been left almost undiscussed until now.

The choice of whether and when to register the inheritance is influenced by the individual's circumstances and economic and social factors; for instance, the property market may become more active due to an upswing in the economy. For example, when land prices rise due to the stimulation of property transactions in urban areas, owners have a stronger desire to sell and they will perform inheritance registration in preparation for that, or the owner may register many years after 
receiving the inheritance in order to sell the land if it becomes the target of an increase in public works.

Figure 5.2 shows the transition in the number of cases of title transferal due to inheritance, etc., from among all land registrations. Although the number has been rising in recent years, it is clear that there are fluctuations each year.

When considering the declining demand for land due to depopulation and the changing awareness of people with regard to land, it does not seem likely that inheritance registration will be proactively performed in the future under current structures.

According to the "Land Issue Awareness Survey" conducted every year by the Ministry of Land, Infrastructure, Transport, and Tourism (MLIT), regarding the question, "Is land as valuable an asset as savings or stocks?" those who responded "No" in 2016 were at the highest level (42.1\%) since the study began (Land Economy and Construction Industries Bureau 2017).

This is approximately twice that of the ratio in $1993(21.3 \%)$. In particular, by region, the ratio was higher in rural areas $(43.6 \%)$ than in major urban areas $(39.7 \%)$. As land prices continue to decrease, in many regions, it is difficult to justify the concept of "land as an asset."

Comments from judicial scriveners included the following: "agricultural land and mountain forests are nothing more than a burden, and it is difficult to produce an inheritor"; "recently, there have been cases where consultants have said that clients only want to register residential land and that mountain forests can be left unregistered"; and "although registration should be done for the sake of the next generation, I am hesitant about pushing registration too much."

If the neglect of vacant properties and abandonment of agricultural land is referred to as "neglect of management" by the owner, leaving the name of the deceased person on the registry for decades by failing to register the inheritance can be called "neglect of rights."

However, this issue does not normally come to the surface. It is only when it comes to using agricultural land, promoting countermeasures for vacant properties, or when disasters occur that the reality becomes apparent.

\subsection{Necessary Countermeasures in the Future}

What countermeasures may be required in the future?

Interviews conducted by the author with relevant parties including local authority officials, legal officials, and real estate-related businesspeople have highlighted three major points in relation to discussions about countermeasures to prevent the unknown ownership issue from worsening. 


\subsubsection{Improving Inheritance Registration}

To prevent the occurrence and increase of the issue of land of unknown ownership, many of the relevant parties pointed out that, in the future, the most important and urgent challenge is inheritance registration.

In the medium term, while promoting a review of the ideals of inheritance registration, first, an improved policy must urgently be sought based on the current voluntary inheritance registration.

Some local authorities are carrying out their own plans locally. In the survey of local authorities mentioned above, one local authority stated that "land that has not been registered as an inheritance is listed as 'Not inherited' on the tax statement issued to taxpayers in April each year. This has led to a gradual increase in inheritance registration."

In addition, it is necessary to prepare several countermeasures according to the type of issue so that inheritance procedures are simplified and so that there is no obstacle to the use of land in areas with outdated registration records.

\subsubsection{Need for a Means to Deal with Land of Unknown Ownership}

The second important point as a countermeasure in relation to this issue is the formation of a means of dealing with and using land where the ownership is unknown. While the population is decreasing, there is more land that is being unused. In the survey of local authorities mentioned above, when asked about the real situation of requests from residents for land contributions, land donated by residents to local authorities was limited mostly to cases in which there was the expectation of official use, such as for roads. Essentially, if an owner is unable to maintain their land, it is preferable that this becomes "everyone's property" or that other structures are put in place to enable new trade or usage methods.

However, currently, such options are limited. It is necessary to create a new means of dealing with such situations from the perspective of land preservation and public good so that the neglect of such unused land does not lead to physical decay or complications in connection to the rights of unregistered inheritances.

\subsubsection{Improving Land Information Infrastructure}

A third point in discussions about countermeasures for the issue of unknown ownership is improving infrastructure relating to land information.

As application for inheritance registration is voluntary, it is difficult to understand landowner information under the current real estate registration system. To 
overcome this fundamental issue, it is necessary to have structures to effectively understand the minimum amount of basic information that is required by making a maximum use of the current registers.

Regarding agricultural land information, the "Agricultural Land Information System" has been operating since 2014 for the centralized management and publication of national agricultural land information. Regarding forests, in the 2016 revision to the Forest Act, municipalities became obligated to maintain a forest register for information such as forest owners and boundary measurements, and to publish those details in part.

In order for the various registers to function effectively, it is important that information is shared between systems to the greatest extent possible. By standardizing the published basic information (owner name, address, date of birth, gender, etc.), ensuring data compatibility, and forming consistent rules, information can be effectively provided and shared.

\subsection{Appropriately Handing Down Land to Future Generations}

Current land systems in Japan were established when Japan was formed as a modern nation in the Meiji era, and they were revised and amended during the period of high economic growth after the war. These systems were formed primarily to deal with "overuse" due to rising land prices and chaotic development rather than depopulation and various accompanying challenges. The issue of land of unknown ownership is a structural challenge that has developed in the gap between the current system and social changes, and there is no panacea for resolving this issue immediately.

First, it is necessary to establish a concept of national land preservation on the premise of population decline and to create various methods suited to each region based on a shared nationwide foundation while also utilizing the systems built up since the Meiji era. In particular, land system reforms cannot be promoted without the understanding of citizens because it is an issue that involves property rights.

In the government's policy guidelines for 2017 that were established by the cabinet in June 2017, regarding the effective use of abandoned and unclaimed land, it was stated that "the aim is to present a bill at the next ordinary session of the Diet." While land prices continue to decrease, and the concept of "land as an asset" ceases to exist, what kind of structures should be formed to hand down land to future generations? Positioning land issues as a challenge for a society with a decreasing population necessitates the promotion of a review of the present system. 


\section{References}

Land Economy and Construction Industries Bureau (2017) Ministry of Land, Infrastructure, Transport and Tourism, Heisei 28-nendo tochi mondai ni kansuru kokumin no ishiki chosa [Survey on Public Attitudes toward Land Issues, Fiscal 2016]

Preliminary Data (2017) Shoyusha fumei tochi mondai kenkyukai, Shoyusha fumei tochi mondai wa kongo doredake hirogaru no ka [How Much Will the Unknown Landowner Problem Grow in the Future? (Preliminary Data)]

Tokyo Foundation for Policy Research (2016) Tochi no "shoyusha fumeika": Jichitai anketo ga shimesu mondai no jittai [Unknown Ownership of Land: what a Survey of Local Authorities Reveals]

Ministry of Justice (1998-2016) Toki Tokei [Registration Statistics], various year

Open Access This chapter is licensed under the terms of the Creative Commons Attribution 4.0 International License (http://creativecommons.org/licenses/by/4.0/), which permits use, sharing, adaptation, distribution and reproduction in any medium or format, as long as you give appropriate credit to the original author(s) and the source, provide a link to the Creative Commons licence and indicate if changes were made.

The images or other third party material in this chapter are included in the chapter's Creative Commons licence, unless indicated otherwise in a credit line to the material. If material is not included in the chapter's Creative Commons licence and your intended use is not permitted by statutory regulation or exceeds the permitted use, you will need to obtain permission directly from the copyright holder.

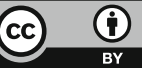

